\title{
Investigation of Possible Maillard Reaction Between Acyclovir and Dextrose upon Dilution Prior to Parenteral Administration
}

\author{
Mohammad Reza Siahi Shadbad, ${ }^{1,2}$ Faranak Ghaderi, ${ }^{1,3}$ Leila Hatami, ${ }^{3}$ and Farnaz Monajjemzadeh ${ }^{1,2,4}$
}

Received 13 October 2015; accepted 31 January 2016; published online 10 February 2016

\begin{abstract}
In this study the stability of parenteral acyclovir (ACV) when diluted in dextrose (DEX) as large volume intravenous fluid preparation (LVIF) was evaluated and the possible Maillard reaction adducts were monitored in the recommended infusion time. Different physicochemical methods were used to evaluate the Maillard reaction of dextrose with ACV to track the reaction in real infusion condition. Other large volume intravenous fluids were checked regarding the diluted drug stability profile. Differential scanning calorimetry (DSC), Fourier transform infrared spectroscopy (FTIR), and mass data proved the reaction of glucose with dextrose. A Maillard-specific high performance liquid chromatography (HPLC) method was used to track the reaction in real infusion condition in vitro. The nucleophilic reaction occurred in diluted parenteral preparations of acyclovir in 5\% dextrose solutions. The best diluent solution was also selected as sodium chloride and introduced based on drug stability and also its adsorption onto different infusion sets (PVC or non PVC) to provide an acceptable administration protocol in clinical practices. Although, the Maillard reaction was proved and successfully tracked in diluted solutions, and the level of drug loss when diluted in dextrose was reported to be between 0.27 up to $1.03 \%$ of the initial content. There was no drug adsorption to common infusion sets. The best diluent for parenteral acyclovir is sodium chloride large volume intravenous fluid.
\end{abstract}

KEY WORDS: incompatibility; large volume intravenous fluid; mass Spectrometry; physicochemical; stability.

\section{INTRODUCTION}

Pharmaceutically interesting compounds can react with the surrounding excipients or media upon formulation or dilution (1-4). Amine-containing drug molecules can react with reducing carbohydrates to form glycosylamines. This type of interaction is named Maillard reaction and is a very well-known chemical incompatibility in pharmaceutical preparations (5-8).

Recently, Maillard reaction has gained special attention in pharmaceutical preformulation studies (9). Different amine-containing drug molecules were subjected to such an interaction and appropriate considerations were made during their formulation $(7,10,11)$. Although the handbook of pharmaceutical excipients, clearly states that "In the aldehyde form, dextrose can react with amines,...," yet no attention is made to dextrose containing large volume intravenous fluid (LVIF) as diluents for the parenteral formulations of amine containing drug molecules (12).

\footnotetext{
${ }^{1}$ Drug Applied Research Center, Tabriz University of Medical Sciences, Tabriz, Iran.

${ }^{2}$ Department of Pharmaceutical and Food Control, Tabriz University of Medical Sciences, Tabriz, 5166414766, Iran.

${ }^{3}$ Student Research Committee, Tabriz University of Medical Sciences, Tabriz, Iran.

${ }^{4}$ To whom correspondence should be addressed. (e-mail: farnaz_m76@yahoo.com)
}

Acyclovir (ACV) is an antiviral drug with common dosage forms as tablets, capsules, and also parenteral preparations.

We were previously shown that $\mathrm{ACV}$ as an aminecontaining drug, undergoes Maillard type reaction with lactose as a filler excipient in solid dosage forms (13). In another research, ACV interacted with sucrose which was used as a sweetener agent in liquid oral formulations (14).

According to clinical guidelines, the ACV parenteral formulations are administered in herpes simplex and varicella zoster in concentrations not more than $5 \mathrm{mg} / \mathrm{mL}$. The stability of ACV in LVIF preparations was first reported in 1989 (15). According to this study, the drug is stable in sodium chloride and dextrose $5 \%$ solutions but a consideration should be done that the diluted solutions must be used within $24 \mathrm{~h}$. In that study, the drug was simply quantified and the stability was concluded when the drug molecule was detected more than $90 \%$ of its initial concentration and no attention was paid to any possible degradation product (s). Recent studies and text books are in accordance withthe findings of Gupta et al. (15-17). At the time of writing this report, FDA guidelines updated in November 2003 by GlaxoSmithKline, states that drug should be diluted in "any appropriate intravenous solution" (18). Recent update of this company on 19 March 2015 represents some detailed information about the administration procedure. 
This product information states that Zovirax IV formulation is known to be compatible, when diluted in accordance with the recommended schedules for $12 \mathrm{~h}$ at room temperature $\left(15\right.$ to $\left.25^{\circ} \mathrm{C}\right)$, but still reports dextrose-containing solutions as compatible ones (19). Some textbooks have introduced a dilution method in sodium chloride intravenous solutions without any prohibition or incompatibility report in dextrose-containing solutions (20).

Although, it is quite possible to assume that the Maillard reaction would take place between $\mathrm{ACV}$ and dextrose but it should be monitored by physicochemical methods in appropriate concentrations and period of time, similar to clinical practice. To the best of our knowledge, no previous study has been done to evaluate the Maillard type interaction of ACV with dextrose upon parenteral administration. To this purpose, the interaction of the mentioned molecule in dextrose diluents was demonstrated using physicochemical methods such as differential scanning calorimetry (DSC), Fourier transform infrared spectroscopy (FTIR), and also mass spectrometry. But going beyond the boundaries of only proving an incompatibility interaction, the reaction was also tracked in real time administration conditions and finally the question of "Does this reaction take place in real infusion condition?" was answered. The absorption of ACV into PVC and non-PVC tubes was also evaluated and the best diluting solution was subsequently introduced.

\section{MATERIALS AND METHODS}

\section{Materials}

Acyclovir sodium salt (ACV) and guanine (GUA) reference standards were purchased from (Tehran, Iran). Dextrose was from Merck (Darmstadt, Germany). All mobile phase constituents were from HPLC grade and obtained from Scharlau Chemie (Barcelona, Spain). All solvents and additives used in adduct synthesis were of extra pure grades and obtained from Scharlau Chemie (Barcelona, Spain).

\section{Methods}

Methods have been divided into three main categories; physicochemical evaluations, adducts synthesis, and real time infusion evaluation.

\section{Physicochemical Evaluations}

DSC

A differential scanning calorimeter (DSC-60, Shimadzu, Japan) was used for thermal analysis of drug and binary mixtures in a $1: 1 \mathrm{w} / \mathrm{w}$ ratio. Individual samples (drug and excipients) as well as physical mixtures of drug and excipients were weighed to about $5 \mathrm{mg}$ in the DSC aluminum pan and scanned in the temperature range of $25-300^{\circ} \mathrm{C}$. A heating rate of $20^{\circ} \mathrm{C}$ per minute was applied and the curves were analyzed by enthalpy calculations using TA-60 software (version 1.51).
FTIR

FTIR spectra of drug and drug-excipient blends were recorded for pure components and also after incubation at elevated temperatures according to Serajuddin et al., on a FTIR spectrophotometer (Bomem, MB-100 series, Quebec, Canada) in the range of $400-4000 \mathrm{~cm}^{-1}$ using potassium bromide disks (6). The spectrum was a mean of ten consecutive scans on the same sample. Processing of the FTIR data was performed using GRAMS/32 version 3.04 (Galactic Industries Corporation, Salem, NH). Different binary mixtures of drug with common diluents as well as controls were evaluated.

\section{HPLC}

System 1. The HPLC system consisted of a system controller, degasser, liquid chromatograph, and a UV-Vis detector all from Cecil (Cecil, UK). Samples were injected onto a C18 column (150 mm, $4.60 \mathrm{~mm}, 5 \mathrm{~lm}$; Waters, USA) and maintained at ambient temperature. A stability indicating HPLC method was used to check the amount of remaining drug in the samples. The eluting solution was a mixture of methanol to distilled water (DW) (10:90) and was eluted at $1 \mathrm{~mL} / \mathrm{min}$ flow rate. The detection was performed at $252 \mathrm{~nm}$. All samples were diluted to a nominal concentration of $50 \mu \mathrm{g} /$ $\mathrm{ml}$ by mobile phase. Guanine (GUA) standard stock was prepared using sodium hydroxide in water $(16 \mu \mathrm{g} / \mathrm{mL})$. Further dilutions were made using mobile phase $(7 \mu \mathrm{g} / \mathrm{mL})(21)$.

System 2. A different HPLC system specific for the Maillard reaction of ACV according to our previous study was applied to analyze a binary mixture sample treated by Serajuddin et al. method and also the prepared adducts mixture $(6,13)$. Briefly, the mobile phase was consisted of $95 \%$ solution A (DW) and 5\% of solution B (95:4.9:0.1 of DW: acetonitrile: formic acid) and was eluted at $1 \mathrm{~mL} / \mathrm{min}$ (13). The detection was performed at $250 \mathrm{~nm}$ and the column length and temperature was $25 \mathrm{~cm}$ and ambient, respectively. Peak collection was performed subsequently to provide mass analysis samples. Adducts mixture was synthetized as follows.

\section{Adducts Synthesis}

According to our previous study, an aqueous method was applied to prepare adducts of the proposed Maillard reaction, with minor modification (13). Briefly, ACV (1 g) and glucose monohydrate $(2 \mathrm{~g})$ were dissolved in $100 \mathrm{~mL}$ of United States Pharmacopeia (USP) borate buffer $(0.1 \mathrm{M}, \mathrm{pH}=9.2)$ with the aid of stirring and ultrasound. Triethylamine and sodium hydroxide were added in an equimolar ratio with ACV to aid solubility as well as reaction incidence. The cloudy white reaction mixture was changed to a clear solution upon heating at a refluxed condition at $100^{\circ} \mathrm{C}$ on a heater stirrer (Velp, Italy) for $14 \mathrm{~h}$ and analyzed in liquid state using mass spectroscopy and referred to as aqueous reaction adducts (ARA).

\section{Mass Spectrometry}

Mass spectrometric detection was performed with a Waters ZQ Mass 2000 (Waters, USA) spectrometer equipped 
with an electrospray ionization (ESI) interface in the positive ion mode and a single quadrupole Mass analyzer. All data were evaluated using Mass lynx version 4.01 software.

Cone, extractor, and RF lens voltages were set at 3.5, 30, 3 and $0.5 \mathrm{~V}$, respectively. Source and desolvation temperatures were maintained at 80 and $200^{\circ} \mathrm{C}$, respectively. Cone and desolvation nitrogen gas flow were at 60 and $300 \mathrm{~L} / \mathrm{h}$.

\section{Real Time Infusion Evaluation}

According to the manufacturer, the parenteral forms of the drug should be diluted to concentrations of about $5 \mathrm{mg} / \mathrm{mL}$ and be infused within not less than $1 \mathrm{~h}$. The same procedure was followed and the ARA was tracked using mass spectrometry.

\section{Selection of the Best Diluent Solution}

Residual drug and its major degradation product (guanine) were determined in different intravenous infusion liquids $(\mathrm{NaCl}$, dextrose and Ringer) and in different infusion sets (PVC (normal or colored), non PVC (PE)) and polyethylene bags. HPLC system 1 was applied for the quantification purpose.

Additional DSC studies were made to reveal the best diluent solution. Then the possibility of the Maillard reaction was checked using a specific HPLC method as well as mass spectrometry.

\section{Statistical Analysis}

Means were compared using the one-way analysis of variance (ANOVA) with a significance level of 0.05 whenever needed, using SPSS 17 software.

\section{RESULTS AND DISCUSSION}

All material section was divided into two main parts: (1) physicochemical evaluations and (2) real time infusion evaluation. The first DSC, FTIR, HPLC and mass parts are for monitoring possible physicochemical changes and to find a way for tracking real infusion condition at last. Thus, physicochemical evaluations have been performed on solid materials in a concentrated condition to force the chemical reaction to take place.

\section{DSC}

DSC has been widely used in monitoring the presence of incompatibility in pharmaceutical preparations (22-31). Compatibility data should be interpreted carefully as lots of deviations from principal laws can be explained. According to Fig. 1a, the melting endotherm of pure ACV was recorded at $255.27^{\circ} \mathrm{C}$. Two other endotherms were exhibited at 176.02 and $120.14^{\circ} \mathrm{C}$ and can be related to the polymorphic and hydrated structure of the ACV powder, respectively. This thermal behavior proves the polymorph VI of ACV (32). This polymorph readily absorbs water and changes to polymorph $\mathrm{V}$ which is a commercial polymorph of $1: 2 \mathrm{ACV} / \mathrm{H} 2 \mathrm{O}$ hydrate. Pure dextrose (DEX) shows a transition at $167.5^{\circ} \mathrm{C}$ which is due to melting. In binary mixtures of ACV-DEX regardless of the ratio of the components the melting endotherm of ACV is missing which indicates an incompatibility between components. As shown in Fig. 1b DEX melts at $167.50^{\circ} \mathrm{C}$ which has been disappeared partially and fully in 1:1 and 1:10 binary mixtures (Fig. 1c, d). It should be kept in mind that changes in DSC thermal profiles can have many possible explanations and certainly not proof of "incompatibility"-for example, it can simply indicate a miscibility of two components and hence the original single melting points can be changed.

Two new endothermic peaks appeared in binary mixtures at 91.68 and $152.73^{\circ} \mathrm{C}$. Surprisingly, the intensity of the new peaks increased with increasing the drug to DEX ratio from 1:1 to $1: 10$. It can be assumed that the first peak at $91.68^{\circ} \mathrm{C}$ can be mainly due to water loss and the second one may be related to incompatibility between the components. Water loss in water-free pure components may be attributed to a waterproducing reaction such as Maillard reaction. As mentioned, it is necessary to examine these assumptions in more details using some other physicochemical analysis to prove the incompatibility.

\section{FTIR}

Vibrational spectroscopy is based on the absorption of infrared radiation by the covalent bonds between different atoms and, thus, is capable of revealing small changes in the structure of a molecule. Functional groups which are consumed and or produced during a chemical reaction can be easily tracked using infrared spectroscopy. Pure ACV showed main absorption peaks at 1717 and $1632 \mathrm{~cm}^{-1}$ due to $\mathrm{C}=\mathrm{O}$ and $\mathrm{N}-\mathrm{H}$ bending. FTIR spectrum of ACV to DEX mixture (1:1) treated by the Serajuddin et al. method has been illustrated in Fig. 2. The treatment was performed briefly as follows: to $200 \mathrm{mg}$ of the solid mixture, 10 or $20 \% \mathrm{w} / \mathrm{w}$ DW was added and incubated at $70^{\circ} \mathrm{C}$ for a 1-week period. A new functional group vibration appeared at about $1679.06 \mathrm{~cm}^{-1}$ which indicated a $-\mathrm{C}=\mathrm{N}$ or imine $\left(1640-1690 \mathrm{~cm}^{-1)}\right.$ formation which was supposed to be produced in the Maillard reaction of the drug and DEX $(13,33)$.

\section{HPLC}

Two HPLC methods have been utilized in this study according to Methods section. The first one was a stabilityindicating method previously used by other researchers to check the ACV stability in stress conditions (21).

The United States Food and Drug Administration (USFDA) stability guideline of 1987 defines stability indicating methods as:" Quantitative analytical methods that are based on the characteristic structural, chemical or biological properties of each active ingredient of a drug product and that will distinguish each active ingredient from its degradation products so that the active ingredient content can be accurately measured." (34).

The data presented in Table I is extracted from this method. The second HPLC method is capable for detecting the maillard reaction initial condensation product which was designed for ACV-Lactose previously. Here we tested it for ACV-DEX and we showed that it was able to track the initial condensation product for the maillard reaction of ACV and DEX. 


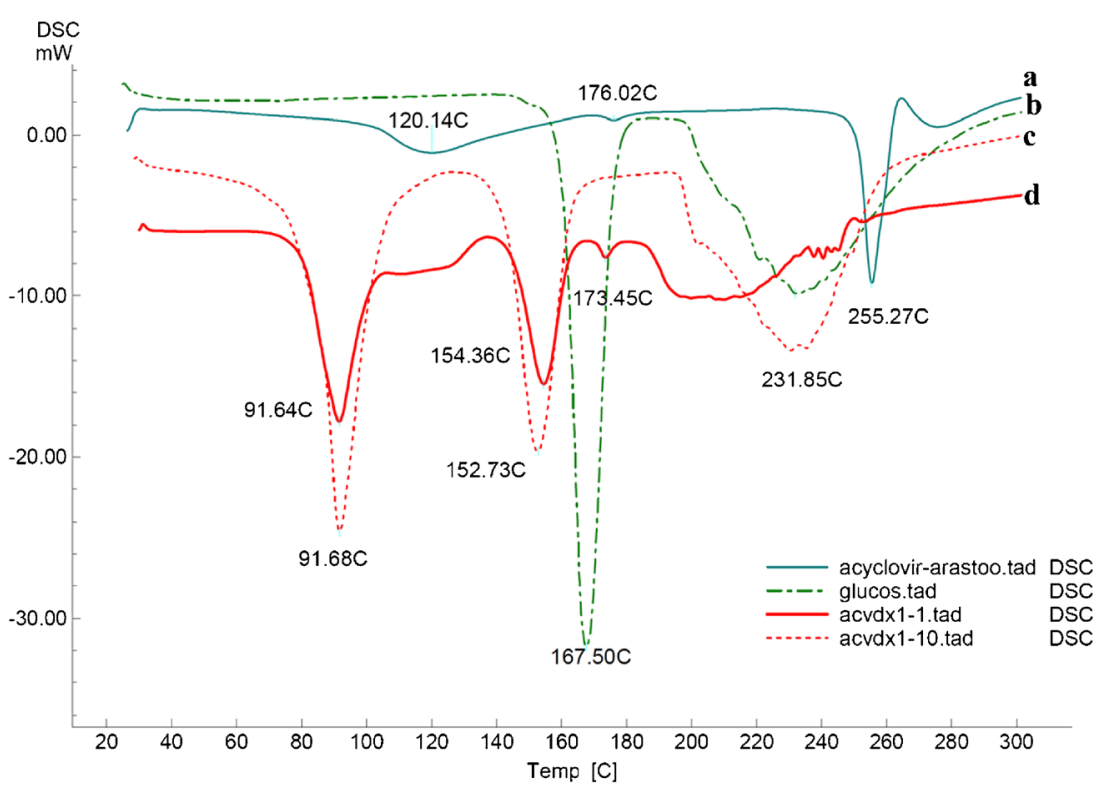

Fig. 1. DSC curves of $a$ pure acyclovir, $b$ pure dextrose, $c$ 1:10 $w / w$ binary mixture of acyclovir and dextrose, and $d 1: 1 w / w$ binary mixture of acyclovir and dextrose

The effect of diluent type as LVIF (sodium chloride, dextrose and ringer) and the infusion set composition (PVC, nonPVC, and colored) on the amount of delivered drug during infusion were evaluated. Some drugs such as insulin show a high tendency toward absorption to PVC surfaces (35-38).

GUA has been known as a related compound of the ACV in USP and also its main degradation product during stress conditions (21). All stability-indicating methods introduce quantification for guanine as a degradation marker. Thus the amount of the remaining drug and also produced GUA were calculated from the HPLC peak responses. Table I represents the results.

When $90 \%$ of a drug is delivered through the infusion system, the drug is considered stable. According to results, ACV remains stable during a 2-h period infusion in all tested samples as the amount of the remaining drug is more than $95 \%$ in all records. Thus it can be concluded that the type of LVIF as a diluent and also the composition of the infusion sets in parenteral administration of ACV dose not alter the drug stability significantly ( $p$ value $>0.05$ ). Polyethylene reservoir bags had no stability effect on the remaining drug in the usual administration protocol and the effect of ambient light was ignorable ( $p$ value $>0.05)$. These findings are in accordance with Dewulf et al. (17).

Additional thermal DSC analysis revealed that the best diluent is to be sodium chloride as no interaction can be seen in DSC curve of this diluent in different composition ratios (Fig. 3a).

In Ringer solutions, the presence of a divalent salt such as calcium but not potassium chloride seems to induct an instability by removing the melting endotherm of the drug molecule in 1:10 ratio completely (Fig. 3b, c). More study is needed to explain this incompatibility.

Although these finding are directly correlated with previous results, (15) Gupta et al. measured the chemical stability of ACV in dextrose $5 \% \mathrm{w} / \mathrm{v}$ and sodium chloride $0.9 \% \mathrm{w} / \mathrm{v}$ injections using a stability-indicating method and concluded that the drug molecule is very stable in both admixtures and

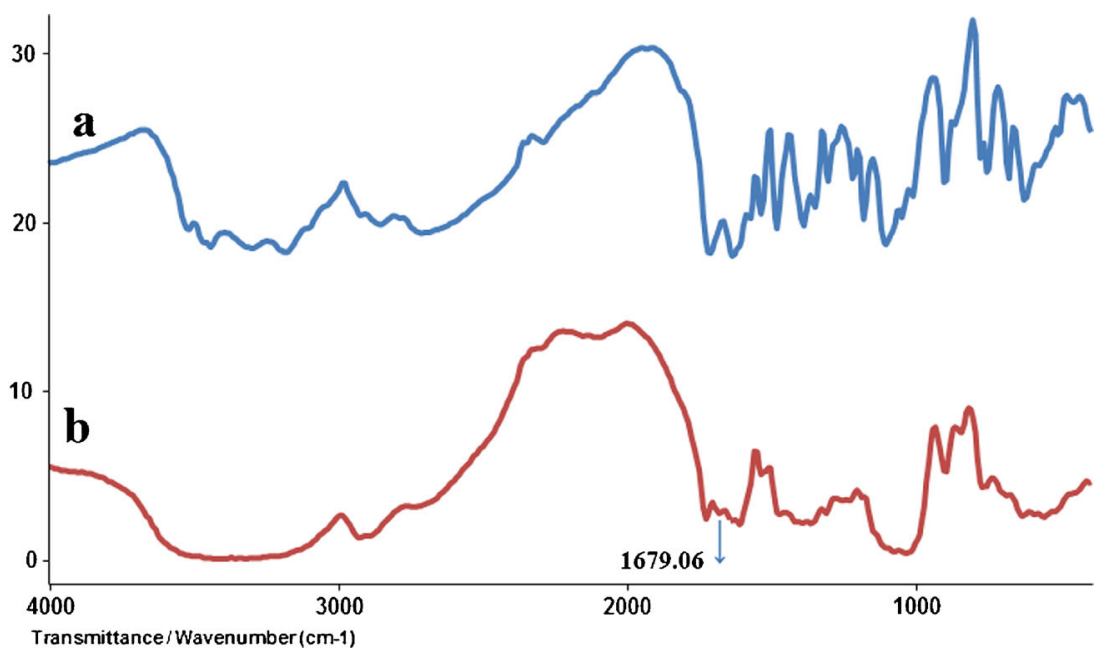

Fig. 2. FTIR spectrum of $a$ Pure acyclovir and $b$ treated acyclovir: dextrose 1:1 mixture 
Table I. The Effect of Diluent Type as LVIF (Sodium Chloride, Dextrose and Ringer) and the Infusion Set Composition (PVC, Non-PVC, and Colored) on the Amount of Delivered Drug During Infusion

\begin{tabular}{|c|c|c|c|c|c|c|c|c|c|c|c|c|c|}
\hline \multicolumn{2}{|l|}{ Type of LVIF } & \multicolumn{4}{|c|}{ Sodium chloride $(\mathrm{NaCl})$} & \multicolumn{4}{|c|}{ Dextrose } & \multicolumn{4}{|c|}{ Ringer } \\
\hline $\begin{array}{l}\text { Type of reservior or } \\
\text { infusion set }\end{array}$ & time & A & $\mathrm{B}$ & $\mathrm{C}$ & $\mathrm{D}$ & A & $\mathrm{B}$ & $\mathrm{C}$ & $\mathrm{D}$ & A & $\mathrm{B}$ & $\mathrm{C}$ & $\mathrm{D}$ \\
\hline $\begin{array}{l}\text { acyclovir }(\% \\
\text { remaining) } \pm \text { SD }\end{array}$ & $1 \mathrm{~h}$ & $\begin{array}{l}99.62 \\
\pm 0.63\end{array}$ & $\begin{array}{l}99.60 \\
\pm 1.95\end{array}$ & $\begin{array}{l}99.73 \\
\pm 0.11\end{array}$ & $\begin{array}{l}99.83 \\
\pm 1.53\end{array}$ & $\begin{array}{l}99.60 \\
\pm 3.31\end{array}$ & $\begin{array}{l}99.69 \\
\pm 0.92\end{array}$ & $\begin{array}{l}99.43 \\
\pm 0.14\end{array}$ & $\begin{array}{l}99.73 \\
\pm 0.16\end{array}$ & $\begin{array}{l}99.61 \\
\pm 0.83\end{array}$ & $\begin{array}{l}99.34 \\
\pm 1.84\end{array}$ & $\begin{array}{l}99.85 \\
\pm 0.14\end{array}$ & $\begin{array}{l}99.81 \\
\pm 1.66\end{array}$ \\
\hline & $2 \mathrm{~h}$ & $\begin{array}{l}99.19 \\
+135\end{array}$ & $\begin{array}{l}99.07 \\
+2.44\end{array}$ & $\begin{array}{l}99.60 \\
+014\end{array}$ & $\begin{array}{l}99.67 \\
+0.36\end{array}$ & $\begin{array}{l}99.11 \\
+133\end{array}$ & $\begin{array}{l}99.05 \\
+2.5\end{array}$ & $\begin{array}{l}99.41 \\
+252\end{array}$ & $\begin{array}{l}98.97 \\
+0.58\end{array}$ & $\begin{array}{l}99.27 \\
+214\end{array}$ & $\begin{array}{l}99.27 \\
+101\end{array}$ & $\begin{array}{l}99.23 \\
+251\end{array}$ & $\begin{array}{l}99.35 \\
+0.58\end{array}$ \\
\hline Guanine & $1 \mathrm{~h}$ & $\begin{array}{l}4.70 \\
+0.24\end{array}$ & 4.2 & $\begin{array}{l}4.29 \\
+022\end{array}$ & $\begin{array}{l}4.2 \\
+01\end{array}$ & $\begin{array}{l}4.7 \\
+024\end{array}$ & $\begin{array}{l}3.96 \\
+0.08\end{array}$ & $\begin{array}{l}3.8 \\
+0.09\end{array}$ & $\begin{array}{l}3.57 \\
+015\end{array}$ & $\begin{array}{l}4.02 \\
+017\end{array}$ & $\begin{array}{l}3.7 \\
+019\end{array}$ & $\begin{array}{l}3.91 \\
+006\end{array}$ & $\begin{array}{l}3.79 \\
+0.16\end{array}$ \\
\hline$(\mu \mathrm{g} / \mathrm{ml}) \pm \mathrm{SD})$ & $2 \mathrm{~h}$ & $\begin{array}{l}3.88 \\
\pm 0.1\end{array}$ & $\begin{array}{l}4.9 \\
\pm 0.17\end{array}$ & $\begin{array}{l}4.34 \\
\pm 0.21\end{array}$ & $\begin{array}{l}4.4 \\
\pm 0.13\end{array}$ & $\begin{array}{l}4.88 \\
\pm 0.1\end{array}$ & $\begin{array}{l}4.2 \\
\pm 0.3\end{array}$ & $\begin{array}{l}4.12 \\
\pm 0.03\end{array}$ & $\begin{array}{l}3.83 \\
\pm 0.18\end{array}$ & $\begin{array}{l}4.01 \\
\pm 0.2\end{array}$ & $\begin{array}{l}3.87 \\
\pm 0.04\end{array}$ & $\begin{array}{l}4 \pm \\
0.09\end{array}$ & $\begin{array}{l}3.73 \\
\pm 0.09\end{array}$ \\
\hline
\end{tabular}

A, polyethylene infusion bag; B, colored PVC infusion set; C, transparent PVC infusion set; $\mathrm{D}$, non-PVC infusion set

no decomposition was seen after 37 days of storage at 25 and $5^{\circ} \mathrm{C}$. The stability-indicating method used in the quantification of the results was capable in reporting the ACV and GUA
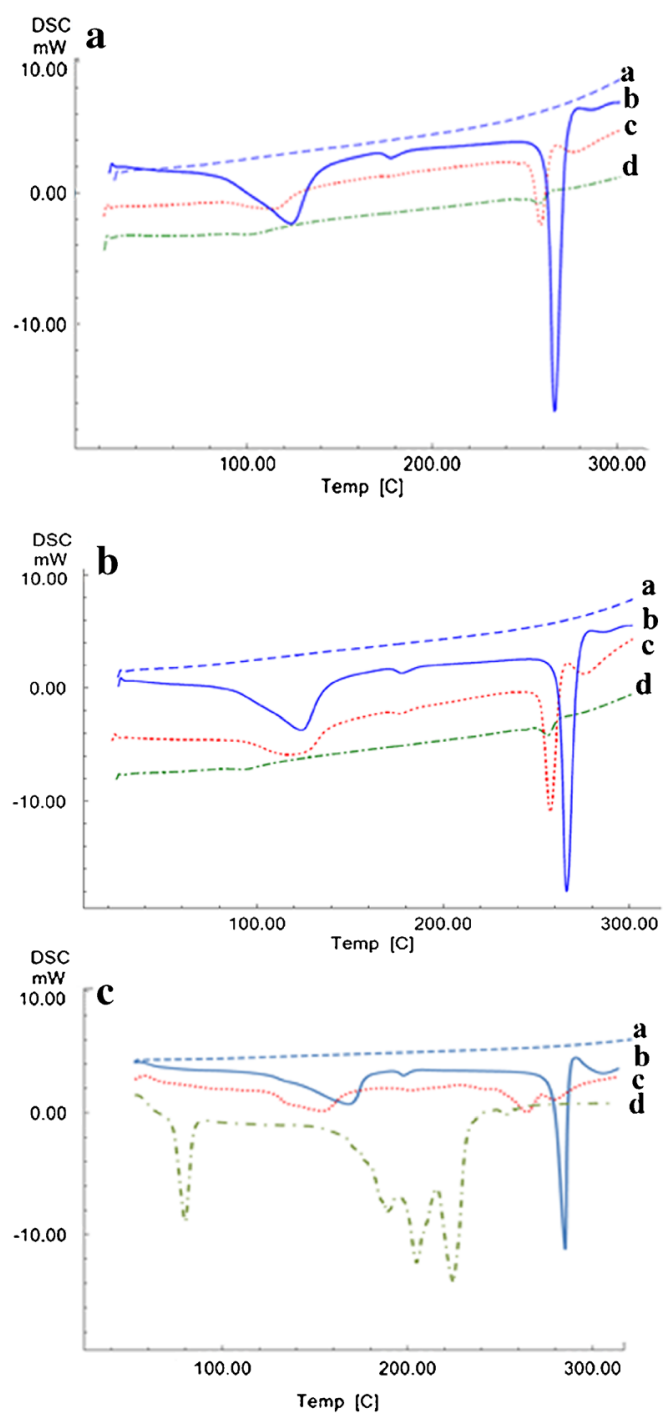

Fig. 3. DSC curves of a sodium chloride, $\mathbf{b}$ potassium chloride, and $\mathbf{c}$ calcium chloride compositions with acyclovir. In each part $a, b, c$, and $d$ refer to pure salt, acyclovir, acyclovir: salt $1: 1$ ratio and acyclovir: salt 1:10 ratio concentrations and consequently any doubt about the Maillard reaction of ACV with dextrose was ignored. Although, a new stability-indicating method was utilized in the present study but the method output was similar to that of Gupta et al. $(15,21)$. Thus, it seems necessary to track the Maillard reaction products in the suspected samples with a suitable HPLC method. The Maillard reaction of ACV with lactose was previously evaluated by the authors and a HPLC method sensitive to Maillard reaction products of ACV was introduced. The mentioned HPLC method was used in this study to track the reaction products in ACV-DEX binary mixtures. The HPLC chromatogram of a binary mixture sample treated by the Serajuddin et al. method and spiked manually with GUA as shown in Fig. 4. The same HPLC behavior was recorded for the synthesized adduct mixture. Thus, it can be concluded that the synthesis method was successful in providing the reaction progress similar to that of treated samples and is, meanwhile, more concentrated to fulfill the preparative purposes. As seen in Fig. 4 there is another peak in about $4 \mathrm{~min}$ in addition to ACV and GUA peaks, which may be related to the Maillard reaction product. Peak 1 was collected in several injections and immediately analyzed using mass spectrometry. Visual findings in different samples are depicted in Fig. 5. Brown

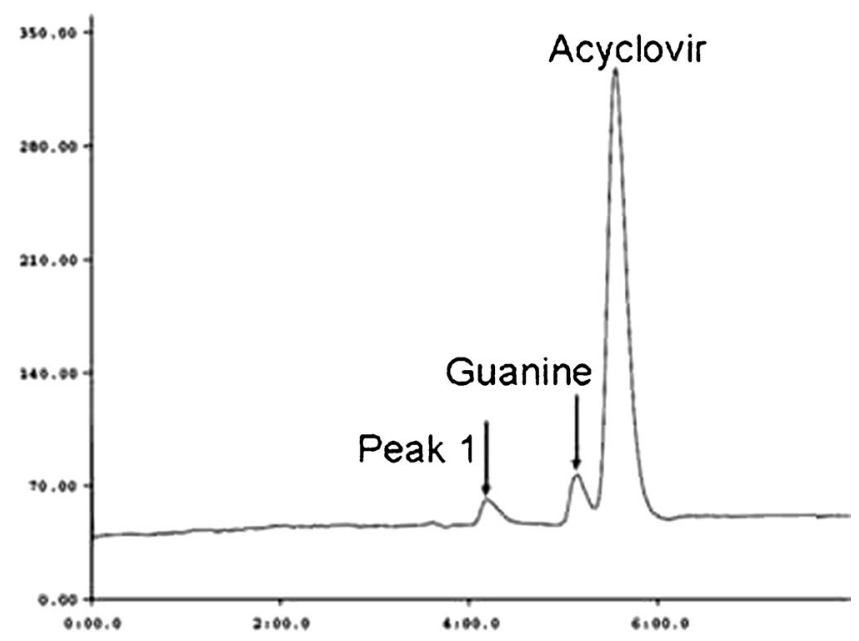

Fig. 4. HPLC chromatogram of treated binary mixture spiked manually with Guanine $(5 \mu \mathrm{g} / \mathrm{ml})$, immediately before injection to the HPLC system 


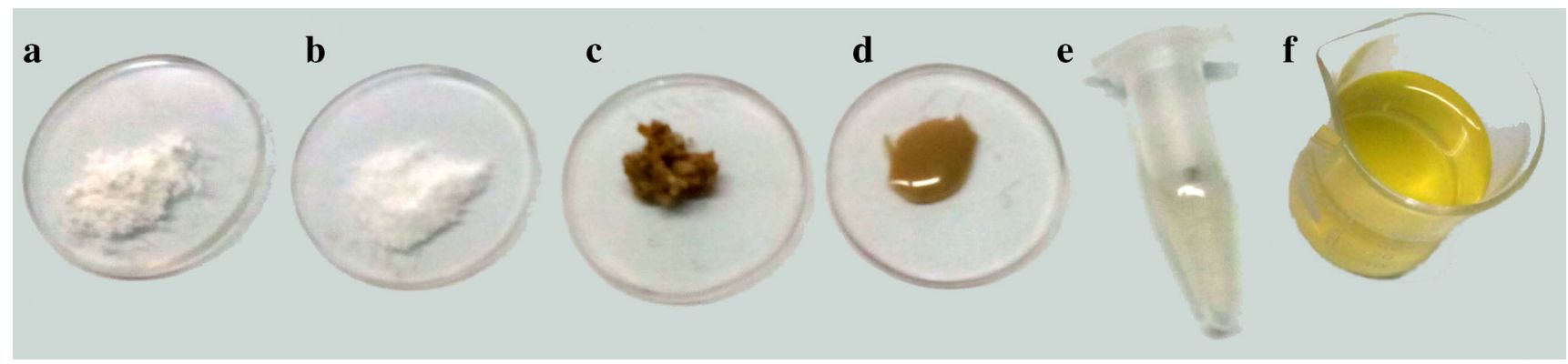

Fig. 5. Visual results for a pure acyclovir powder, $\mathbf{b}$ pure dextrose powder, $\mathbf{c} 1: 1$ treated binary mixture of acyclovir-dextrose with $10 \%$ added water and d with $20 \%$ added water, e acyclovir parenteral formulation diluted in dextrose solution and kept for 3 months at room temperature, and $\mathbf{f}$ synthetized adducts mixture of acyclovir-dextrose

color of the treated samples and also the diluted ACV parenteral formulation in dextrose solution kept for 3 months at room temperature may be related to Maillard browning reaction. No color change was seen after 1 and $2 \mathrm{~h}$ of storage. Recently, some water-free synthesis has been proposed to simulate the Maillard reaction between bisoprolol and dextrose. The results of the present study reveals that aqueous synthesis can completely mimic the reaction of ACV-DEX without any further need to costly and sophisticated water-free synthetic methods.

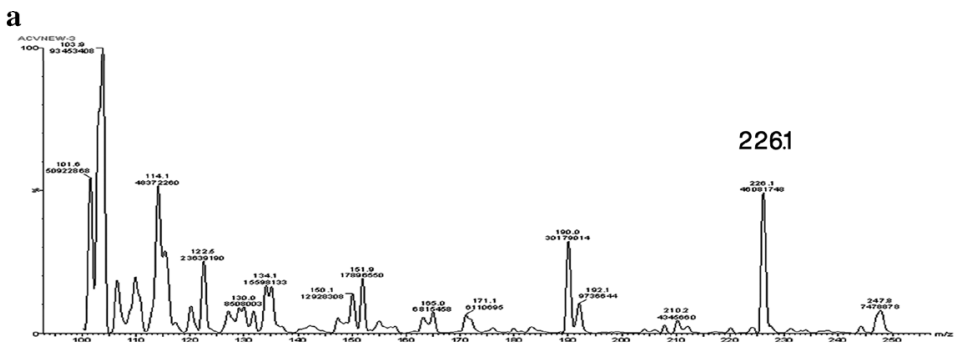

b
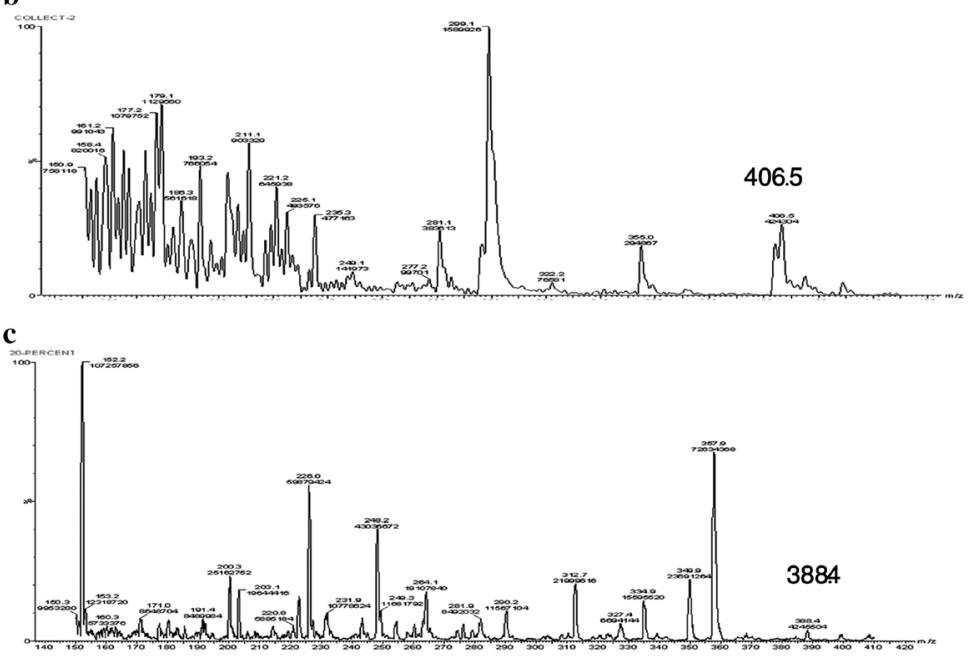

d

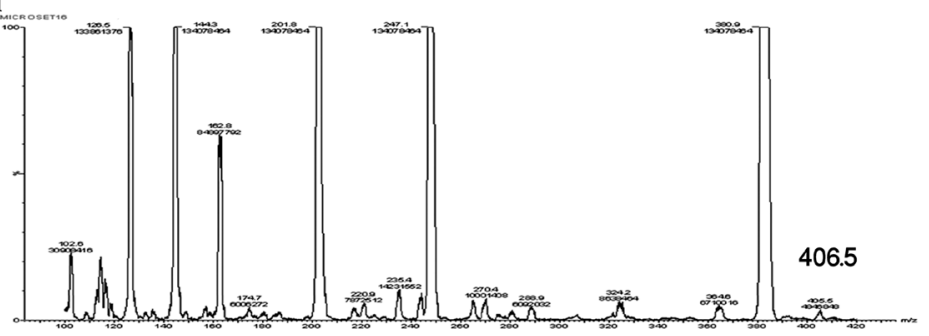

Fig. 6. ESI-quadruple mass spectra of a pure acyclovir, $\mathbf{b}$ manually collected peak 1, c 1:1 treated binary mixture of acyclovir-dextrose with $20 \%$ added water, and $\mathbf{d}$ real infusion sample (acyclovir parenteral preparation diluted in dextrose) 

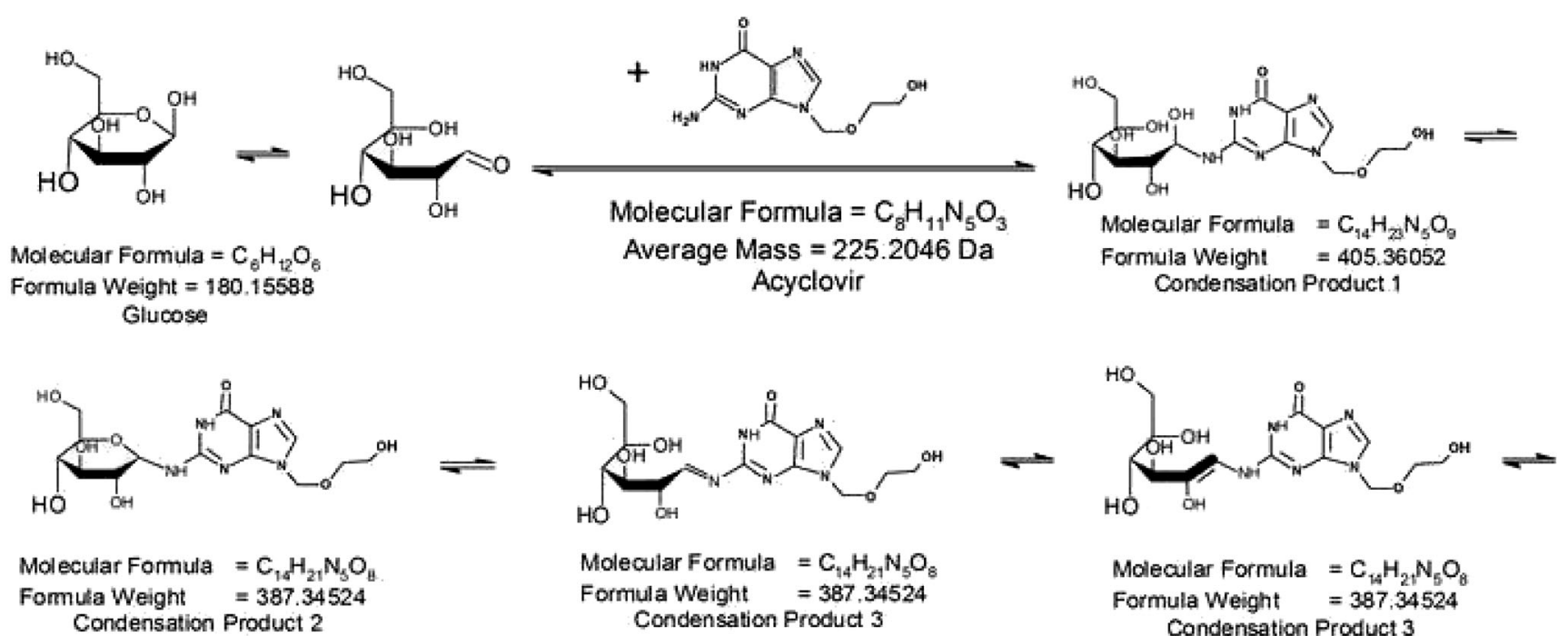

Molecular Formula $=\mathrm{C}_{19} \mathrm{H}_{21} \mathrm{~N}_{3} \mathrm{O}_{\mathrm{i}}$
Formula Weight
Condensation Product 2 Condensation Product 3

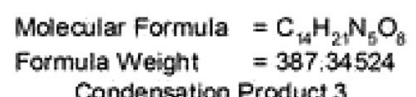

Condensation Product 3

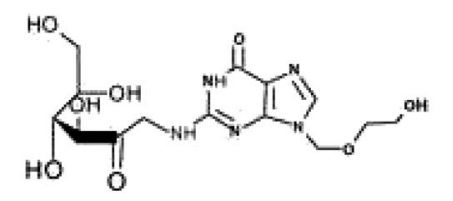

Molecular Formula $=\overline{\mathrm{C}}_{14} \mathrm{H}_{24} \mathrm{~N}_{5} \mathrm{O}_{6}$

Formula Weight $\quad=387,34524$

Condensation Product 4

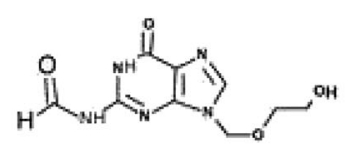

Molecular Formula $=\mathrm{C}_{9} \mathrm{H}_{1}, \mathrm{~N}_{5} \mathrm{O}_{4}$
Formula Weight $=253,21474$
Condensation Product 5

Fig. 7. Proposed Maillard reaction of acyclovir and dextrose

\section{Mass Spectrometry}

Mass results for pure ACV (MW =225.2) and manually collected peak 1 along with the treated sample is depicted in Fig. 6a-c. The ESI in positive mode mass spectra showed that the molecular ions of ACV and peak 1 were the protonated molecules, $[\mathrm{M}+\mathrm{H}]+$ of $\mathrm{m} / \mathrm{z} 226.1$ and 406.5, respectively (Fig. 6a, b). M/z value at 406.5 may be related to protonated condensation product 1 which is a glycosylamine, produced from the reaction of ACV with DEX. The m/z value at 247.8 is the sodium salt of ACV.

Figure $6 \mathrm{c}$ is the mass spectra of treated binary mixtures. The $\mathrm{m} / \mathrm{z}$ value at 388.4 may be related to condensation product 4 shown in Fig. 7. The main fragments in Fig. $4 c$ and $6 b$ appeared at $\mathrm{m} / \mathrm{z}$ values of 299.1 and 357.9. Possible structures of these fragments have been proposed in Fig. 8.

All physicochemical methods including DSC, FTIR and mass spectrometry proved the Maillard reaction of ACV and DEX.

\section{Real Time Infusion Evaluation}

As mentioned before, according to the manufacturer, ACV parenteral forms should be diluted prior or to administration and should be delivered within 1-2 h. The resultant solution was checked after $2 \mathrm{~h}$ to track Maillard reaction products and, finally, to answer the question that "Does the Maillard reaction of ACV and DEX take place in real infusion condition?"

Injectable ACV formulations are lyophilized in the presence of sodium hydroxide (19).

Singh et al. who studied the $\mathrm{pH}$ effect on acyclovir stability reported a potency reduction for acyclovir boiled in $1 \mathrm{~N}$ $\mathrm{H} 2 \mathrm{SO} 4$ for $10 \mathrm{~min}$ for about $12 \%$. Alkaline condition (boiling in $1 \mathrm{~N} \mathrm{NaOH}$ for $10 \mathrm{~min}$ ) decreased the potency to $95 \%$. (39). Later in 2007, Sinha et al. studied the stress conditions on acyclovir stability and reported that the drug was more stable in alkaline conditions compared to acidic stress. The
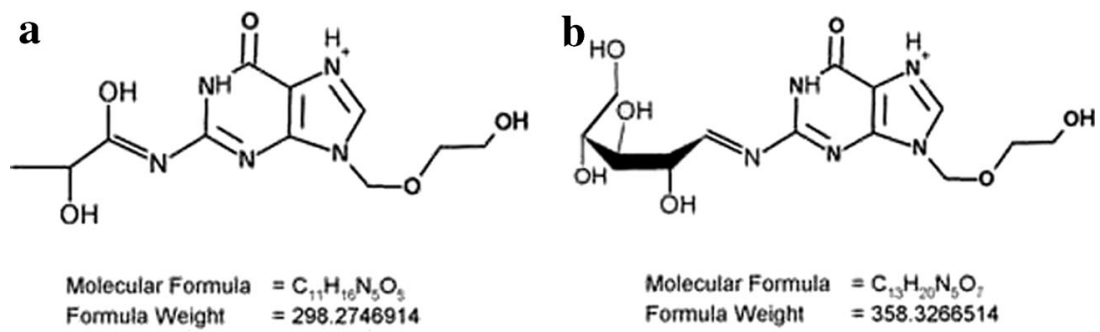

Fig. 8. Proposed structure of main fragments 
remaining drug after exposure to acidic and alkaline stress $\left(1 \mathrm{~N}, 2 \mathrm{~h}\right.$, and $80^{\circ} \mathrm{C}$ ) was 4.44 and $88.65 \%$, respectively (21).

It should be kept in mind that basic $\mathrm{pH}$ values favors the Maillard reaction as a nucleophilic reaction (40).

Figure $4 \mathrm{~d}$ illustrates the mass spectra of the real infusion sample. As shown, the $\mathrm{m} / \mathrm{z}$ value at 405.5 may be related to Maillard reaction of ACV and DEX. Many other different evaluations were made using control samples (i.e., drug-free LVIF).

It can be concluded that the Maillard reaction of ACVDEX can take place in real infusion condition in which ACV parenteral preparations have been diluted with LVIF containing $5 \%$ dextrose.

According to Table I, it shows that the remaining drug in different LVIFs is more than $95 \%$ after $2 \mathrm{~h}$. The total loss can be attributed to both the guanine formation and the maillard reaction progress. All the maillard reaction tracking was done qualitatively and the reason for this was because of the identity of the maillard product reported as an unstable intermediate agent resulting from condensation of ACV with DEX and, thus, cannot be synthesized as a pure material to be used for accurate qualitative calculations. Similar researches have reported the maillard reaction in a similar way $(5,41)$ as well as we have done previously $(9,13,28,29,31,42)$.

\section{CONCLUSION}

In this study, the Maillard reaction of ACV parenteral preparation diluted in Dextrose was identified by physicochemical methods and tracked in real infusion condition in vitro. This should be kept in mind that not only the remaining drug but also the degradation or interaction products, determine the drug stability in a pharmaceutical medium. The best diluent of ACV in parenteral administration was introduced as $0.9 \%$ sodium chloride solutions. No adsorption was shown in PVC or non-PVC tubes used as infusion sets and polyethylene infusion bags in delivering the drug to the patient, and the drug stability was not affected by ambient light during the administration time. Although, the Maillard reaction was proved and successfully tracked in diluted solutions, and there was no drug adsorption to common infusion sets.

In the present research, the level of drug loss when diluted in dextrose solutions was reported to be between 0.27 up to $1.03 \%$ of its initial content. The maximum daily dosage of parenteral acyclovir is reported to be $20 \mathrm{mg} / \mathrm{kg}$; thus, for a $70 \mathrm{~kg}$ adult person, this dosage exceeds $1 \mathrm{~g}$ per day (18). According to ICH guidelines, different degradation thresholds can be specified for such a drug formulation (43). If the degradation product level is more than $0.05 \%$ of the total daily intake (TDI), the level is defined as reporting. But levels more than $0.2 \%$ of TDI may be considered as identification or qualification thresholds.

The loss of drug can be attributed to different degradation or condensation pathways. Although this study has reported and identified the condensation products of ACV and DEX, still more research is needed for quantification purposes. As the levels and safety of the degradation products are not identified yet, even at this stage the findings may trigger just a minor alert.

\section{ACKNOWLEDGMENTS}

This paper was extracted from Pharm.D thesis no. 3684 submitted to the Faculty of Pharmacy of Tabriz University of Medical Sciences and financially supported by grant no 91/112 from the Drug Applied Research Center of the same university.

\section{COMPLIANCE WITH ETHICAL STANDARDS}

Conflict of Interest

The authors declare that they have no

competing interests.

\section{REFERENCES}

1. Bharate SS, Bharate SB, Bajaj AN. Incompatibilities of pharmaceutical excipients with active pharmaceutical ingredients: a comprehensive review. J Excip Food Chem. 2010;1(3):3-26.

2. Monajjemzadeh F, Farjami A. Common problems in stress testing of pharmaceutical preparations. J Mol Pharm Org Process Res. 2014;2:e117.

3. Monajjemzadeh F. LC-mass as a complementary method in detecting drug-excipient incompatibility in pharmaceutical products. J Mol Pharm Org Process Res. 2014;2:e110.

4. Monajjemzadeh F, Ebrahimi F, Zakeri-Milani P, Valizadeh H. Effects of formulation variables and storage conditions on light protected vitamin B12 mixed parenteral formulations. Adv Pharm Bull. 2014;4(4):329.

5. Abdoh A, Al-Omari MM, Badwan AA, Jaber AM. Amlodipine besylate-excipients interaction in solid dosage form. Pharm Dev Technol. 2004;9(1):15-24.

6. Serajuddin A, Thakur AB, Ghoshal RN, Fakes MG, Ranadive $\mathrm{SA}$, Morris KR, et al. Selection of solid dosage form composition through drug-excipient compatibility testing. J Pharm Sci. 1999;88(7):696-704.

7. Wirth DD, Baertschi SW, Johnson RA, Maple SR, Miller MS, Hallenbeck DK, et al. Maillard reaction of lactose and fluoxetine hydrochloride, a secondary amine. J Pharm Sci. 1998;87(1):31-9.

8. Monajjemzadeh F, Hassanzadeh D, Valizadeh H, Siahi-Shadbad MR, Mojarrad JS, Robertson TA, et al. Detection of gabapentinlactose Maillard reaction product (Schiff's base): application to solid dosage form preformulation. Part 1. Pharm Ind. 2011;73(1):174-7.

9. Monajjemzadeh F, Hassanzadeh D, Valizadeh H, SiahiShadbad MR, Mojarrad JS, Robertson T, et al. Assessment of feasibility of Maillard reaction between baclofen and lactose by liquid chromatography and tandem mass spectrometry, application to pre formulation studies. AAPS PharmSciTech. 2009;10(2):649-59.

10. Qiu Z, Stowell JG, Morris KR, Byrn SR, Pinal R. Kinetic study of the Maillard reaction between metoclopramide hydrochloride and lactose. Int J Pharm. 2005;303(1-2):20-30.

11. Harmon PA, Yin W, Bowen WE, Tyrrell R, Reed RA. Liquid chromatography-mass spectrometry and proton nuclear magnetic resonance characterization of trace level condensation products formed between lactose and the amine-containing diuretic hydrochlorothiazide. J Pharm Sci. 2000;89(7):920-9.

12. Rowe RC, Sheskey PJ, Quinn ME, A.P. Association, and P. Press. Handbook of pharmaceutical excipients. Vol. 6. Pharmaceutical press London. 2009.

13. Monajjemzadeh F, Hassanzadeh D, Valizadeh H, Siahi-Shadbad MR, Mojarrad JS, Robertson TA, et al. Compatibility studies of acyclovir and lactose in physical mixtures and commercial tablets. Eur J Pharm Biopharm. 2009;73(3):404-13.

14. Desai D, Rao V, Guo H, Li D, Bolgar M. Stability of low concentrations of guanine-based antivirals in sucrose or maltitol solutions. Int J Pharm. 2007;342(1):87-94. 
15. Gupta VD, Pramar Y, Bethea C. Stability of acyclovir sodium in dextrose and sodium chloride injections. J Clin Pharm Ther. 1989;14(6):451-6.

16. Zhang Y, Trissel LA, Martinez JF, Gilbert DL. Stability of acyclovir sodium 1,7 , and $10 \mathrm{mg} / \mathrm{mL}$ in $5 \%$ dextrose injection and $0.9 \%$ sodium chloride injection. Am J Health Syst Pharm. 1998;55(6):574-7.

17. Dewulf J, Galanti L, Godet M, Gillet P, Jamart J, Hecq J-D. Long-term stability of acyclovir in $0.9 \% \mathrm{NaCl}$ infusion polyolefin bags at $5 \pm 3^{\circ} \mathrm{C}$ after freeze-thaw treatment: a generic product versus the brand name. In Annales Pharmaceutiques Francaises. 2015: Elsevier.

18. US-FDA. ZOVIRAX, Prescribing Information. 2003 November 2003 [cited; Available from: http://www.accessdata.fda.gov/ drugsatfda_docs/label/2004/18603slr027_zovirax_lbl.pdf.

19. GlaxoSmithKline. Zovirax IV 250mg, 500mg. 201519 March 2015 [cited; Available from: https://www.medicines.org.uk/emc/ medicine/2191.

20. Martindale W, Sweetman SC. Martindale: the complete drug reference. London: Pharmaceutical Press; 2015.

21. Sinha V, Trehan A, Kumar M, Singh S, Bhinge J. Stress studies on acyclovir. J Chromatogr Sci. 2007;45(6):319-24.

22. de Barros Lima ÍP, Lima NGP, Barros DM, Oliveira TS, Mendonça CM, Barbosa EG, et al. Compatibility study between hydroquinone and the excipients used in semi-solid pharmaceutical forms by thermal and non-thermal techniques. J Therm Anal Calorim. 2015;120(1):719-32.

23. Pramod K, Suneesh CV, Shanavas S, Ansari SH, Ali J. Unveiling the compatibility of eugenol with formulation excipients by systematic drug-excipient compatibility studies. J Anal Sci Technol. 2015;6(1):1-14.

24. Wissing S, Craig DQ, Barker SA, Moore WD. An investigation into the use of stepwise isothermal high sensitivity DSC as a means of detecting drug-excipient incompatibility. Int J Pharm. 2000;199(2):141-50.

25. Hamishehkar H, Valizadeh H, Alasty P, Monajjemzadeh F. Spray drying as a fast and simple technique for the preparation of extended release dipyridamole (DYP) microparticles in a fixed dose Combination (FDC) product with aspirin. Drug Res. 2014;64(2):104-12.

26. Monajjemzadeh F, Hamishehkar H, Zakeri-Milani P, Farjami A, Valizadeh H. Design and optimization of sustained-release divalproex sodium tablets with response surface methodology. AAPS PharmSciTech. 2013;14(1):245-53.

27. Hasanzadeh D, Ghaffari S, Monajjemzadeh F, Al-Hallak M-K, Soltani G, Azarmi S. Thermal treating of acrylic matrices as a tool for controlling drug release. Chem Pharm Bull. 2009;57(12):135662.

28. Ghaderi F, Nemati M, Siahi-Shadbad MR, Valizadeh H, Monajjemzadeh F. DSC kinetic study of the incompatibility of doxepin with dextrose. J Therm Anal Calorim. 1-10. 2015.

29. Ghaderi F, Nemati M, Siahi-Shadbad MR, Valizadeh H, Monajjemzadeh F. Physicochemical evaluation and non- isothermal kinetic study of the drug-excipient interaction between doxepin and lactose. Powder Technol. 2015.

30. Monajjemzadeh F, Ghaderi F. Thermal analysis methods in pharmaceutical quality control. J Mol Pharm Org Process Res. 2015;3:e121.

31. Ghaderi F, Nemati M, Siahi-Shadbad MR, Valizadeh H, Monajjemzadeh F. Non isothermal decomposition kinetics and compatibility studies of doxepin with sucrose. Pharm Ind. 2015;77(8):1222-8.

32. Lutker KM, Quiñones R, Xu J, Ramamoorthy A, Matzger AJ. Polymorphs and hydrates of acyclovir. J Pharm Sci. 2011;100(3):949-63.

33. Namli H, Turhan O. Background defining during the imine formation reaction in FT-IR liquid cell. Spectrochim Acta A Mol Biomol Spectrosc. 2006;64(1):93-100.

34. U.S.F.a.D. Administration, guideline for submitting documentation for the stability of human drugs and biologics. 1987: Rockville, $\mathrm{MD}$.

35. Dine T, Luyckx M, Cazin J, Brunet C, Cazin M, Goudaliez F, et al. Stability and compatibility studies of vinblastine, vincristine, vindesine and vinorelbine with PVC infusion bags. Int J Pharm. 1991;77(2):279-85.

36. Jelvehgari M, Milani PZ, Siahi-Shadbad MR, Monajjemzadeh F, Nokhodchi A, Azari Z, et al. In vitro and in vivo evaluation of insulin microspheres containing protease inhibitor. Drug Res. 2011;61(1):14-22.

37. Dine T, Khalfi F, Gressier B, Luyckx M, Brunet C, Ballester L, et al. Stability study of fotemustine in PVC infusion bags and sets under various conditions using a stability-indicating high-performance liquid chromatographic assay. J Pharm Biomed Anal. 1998;18(3):373-81.

38. Faouzi M, Dine T, Luyckx M, Goudaliez F, Mallevais M, Gressier $\mathrm{B}$, et al. Stability and compatibility studies of cephamandole nafate with PVC infusion bags. J Pharm Biomed Anal. 1994;12(1):99-104.

39. Singh S, Bakshi M. Stress test to determine inherent stability of drugs. Pharm Technol. 2000;4:1-14.

40. Szalka M, Lubczak J, Naróg D, Laskowski M, Kaczmarski K. The Maillard reaction of bisoprolol fumarate with various reducing carbohydrates. Eur J Pharm Sci. 2014;59:1-11.

41. Qiu Z, Stowell JG, Morris KR, Byrn SR, Pinal R. Kinetic study of the Maillard reaction between metoclopramide hydrochloride and lactose. Int J Pharm. 2005;303(1):20-30.

42. Monajjemzadeh F, Hassanzadeh D, Valizadeh H, Siahi-Shadbad MR, Mojarrad JS, Robertson TA, Roberts MS. Detection of gabapentin-lactose Maillard reaction product (Schiff's Base): application to solid dosage form preformulation. Part 1. pharmind: Die Pharmazeutische Industrie. 73(1):174-177. 2011.

43. I.H.T. Guideline. Impurities in new drug substances Q3A (R2). In: Proceedings of the International Conference on Harmonization of Technical Requirements for Registration of Pharmaceuticals for Human Use, Geneva, Switzerland. 2006. 